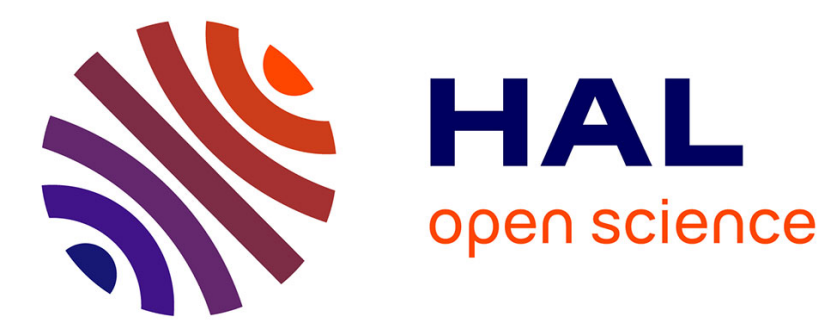

\title{
Liquid-crystal science from 1888 to 1922: Building a revolution
}

\author{
Michel Mitov
}

\section{To cite this version:}

Michel Mitov. Liquid-crystal science from 1888 to 1922: Building a revolution. ChemPhysChem, 2014, 15 (7), pp.1245-1250. 10.1002/cphc.201301064 . hal-01764620

\author{
HAL Id: hal-01764620 \\ https://hal.science/hal-01764620
}

Submitted on 7 Oct 2021

HAL is a multi-disciplinary open access archive for the deposit and dissemination of scientific research documents, whether they are published or not. The documents may come from teaching and research institutions in France or abroad, or from public or private research centers.
L'archive ouverte pluridisciplinaire HAL, est destinée au dépôt et à la diffusion de documents scientifiques de niveau recherche, publiés ou non, émanant des établissements d'enseignement et de recherche français ou étrangers, des laboratoires publics ou privés. 


\title{
Liquid Crystal Science from 1888 to 1922: Building a Revolution
}

\author{
Michel Mitov ${ }^{[1]}$
}

Invited paper for the special issue of ChemPhysChem on liquid crystals.

The saga of liquid crystals started with their discovery in 1888 by the botanist Friedrich Reinitzer, who unexpectedly observed "two melting points" for crystals extracted from the root of a carrot. At the end of the nineteenth century, most scientists did not believe in the existence of "liquid crystals" as promoted by the crystallographer Otto Lehmann. The controversies were very vivid; to the point that the recognition of mesomorphic states of matter by the scientific community required more than two decades. In the end, liquid crystals changed our vision of matter by shattering the threestate paradigm. Since the mid-1970s, liquid crystals have revolutionized the worldwide informationdisplay industry and now play a host of key roles in various technologies.

Keywords: liquid crystals · discovery · history of science · Otto Lehmann

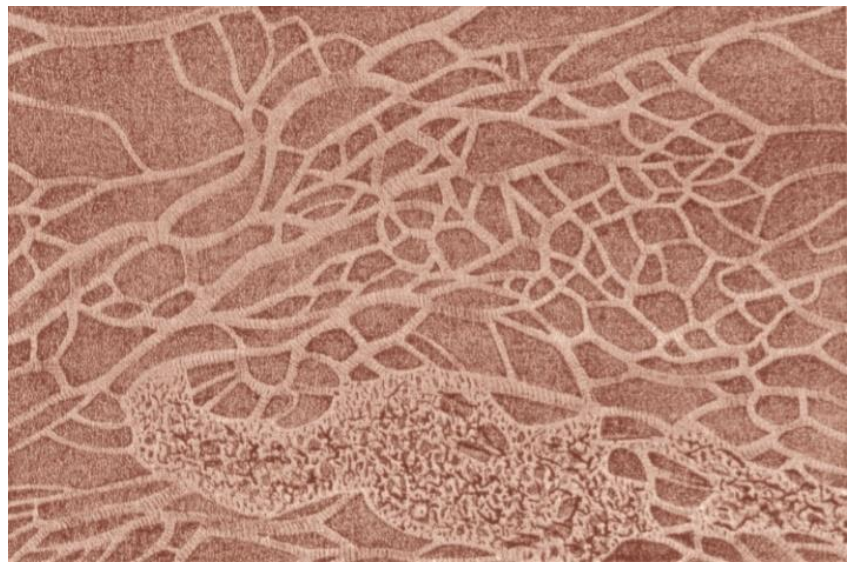

The recognition of the liquid-crystalline states of matter by the scientific community required more than two decades. This paper comes back to the early years of liquid crystal research, at the pivotal period between the nineteenth and twentieth centuries. Amazement, doubt, controversy, struggle, and finally acceptation were the successive steps of liquid crystal history from 1888 to 1907.

https://doi.org/10.1002/cphc.201301064

Article history: Received: November 14, 2013 - Published online on January 31, 2014.

\footnotetext{
${ }^{[1]}$ Centre d'Elaboration de Matériaux et d'Etudes Structurales, CEMES CNRS, Toulouse (France)

Fax: (+33) 562257999

E-mail: mitov AT cemes.fr
} 


\section{Introduction}

A nematic liquid crystal (LC), which is used in flat-panel displays, looks like a school of fish. Rod-like molecules are on average parallel but have no particular position. From this orientational order comes the birefringence property, which is a property of a crystal. These same molecules constantly readjust their position, and this positional disorder gives the fluid state. This view is very far from the traditional view of the states of matter that scientists held during the pivotal period between the nineteenth and twentieth centuries, when, with much heterodoxy, the German physicist Otto Lehmann coined the term "liquid crystals" to describe these materials.

\section{Carrot is ancestor of flat screen}

We were in 1888, at the Institute of Plant Physiology at the German University of Prague. Friedrich Reinitzer (1857-1927; Figure 1) was a botanist-or biochemist in modern terms. He was working on crystals of cholesterol derivatives extracted from a carrot's root [1] and wanted to elucidate their structure. Amazingly, the cholesteryl benzoate had "two melting points." This was exactly the expression Reinitzer used in a letter dated March 14, 1888-sixteen pages long and written in Gothic letters. This letter was addressed to the crystallographer Otto Lehmann (1855-1922; Figure 2), a physicist from the Polytechnical School of Aachen who specialized in growth phenomena and phase transitions in crystalline materials. 


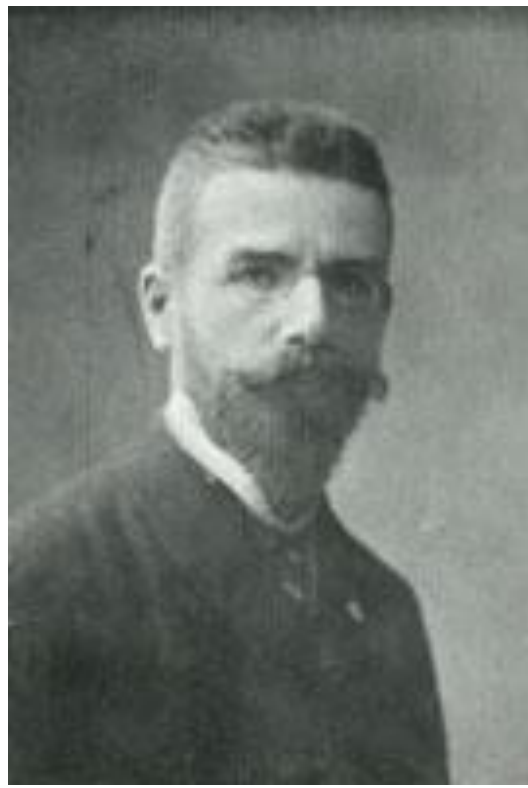

Figure 1. Friedrich Reinitzer was the first scientist to give credit to the unusual temperature behavior of crystals extracted from biological materials - a carrot's root in this case. He understood that this behavior was not an artifact and was worthy of in-depth investigation. For this, he contacted Otto Lehmann.

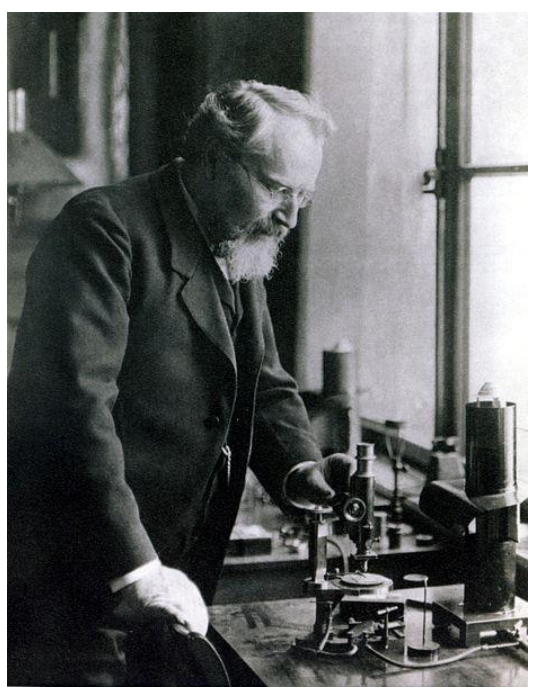

Figure 2. Otto Lehmann reproduced the phenomena seen by Reinitzer in a large number of substances and showed it to be general. He was the key promoter of liquid crystals; both the term and the research activities in the field. He was nominated (unsuccessfully) for the Nobel prize several times beginning in 1913.

Reinitzer explained to his colleague that the small crystals lost their rigidity at $145.5^{\circ} \mathrm{C}$-this "first" melting point was the temperature at which the solid turned into a milky fluid. At $178.5^{\circ} \mathrm{C}$-the "second" melting point, later named the clearing point-the drop of material became perfectly transparent. Upon cooling, the material exhibited violet and blue colors, which then disappeared, leaving the substance cloudy but still liquid. This was surprising in view of current knowledge of crystalline matter at these times: a crystal must lose color and solidity at a single and unique temperature. However, a few decades earlier, in 1854, Rudolf Virchow [2] described similar unusual behavior for myelin-the sheath that surrounds nerve fibers-and Carl von Mettenheimer [3] 
showed that myelin was birefringent. Without realizing the meaning of their observations, these scientists had described the first example of a LC known in the scientific literature. Between 1861 and 1887, chemists had also reported strange color effects in cholesterol esters [4], but the complexity of their observations and the difficulty of duplicating them did not encourage them to pursue their investigations. For this reason, science historians consider that LCs were discovered in 1888 by Reinitzer: he was the first to give a detailed description of his observations and the first to recognize that the strange behavior of these "crystals" was a significant and new phenomenon-not an artifact.

The liquid crystalline phases Reinitzer observed were chiral phases-later named the cholesteric phase and the blue phases. Research activities accelerated when Reinitzer contacted Lehmann, whom he held as a partner of choice not only because he was an experienced crystallographer but also because he had fabricated a whole arsenal of microscopes (Figure 3) that allowed him to make in situ observations of crystals as the temperature changed. It was quite rare to find such apparatus on the shelves of laboratories. Lehmann and Reinitzer exchanged numerous letters and samples in March and April of 1888, and Lehmann observed the substances by polarized-light microscopy (Figure 4) [5]. They knew that "two-step melting" of crystalline matter would excite the curiosity of their colleagues, but they did not anticipate that these observations, and the forthcoming decision to name the substances with the oxymoron "liquid crystals," would trigger polemics and passionate reactions [6-8]. Reinitzer was out of the subject as soon as Lehmann took control of operations, but 
Review
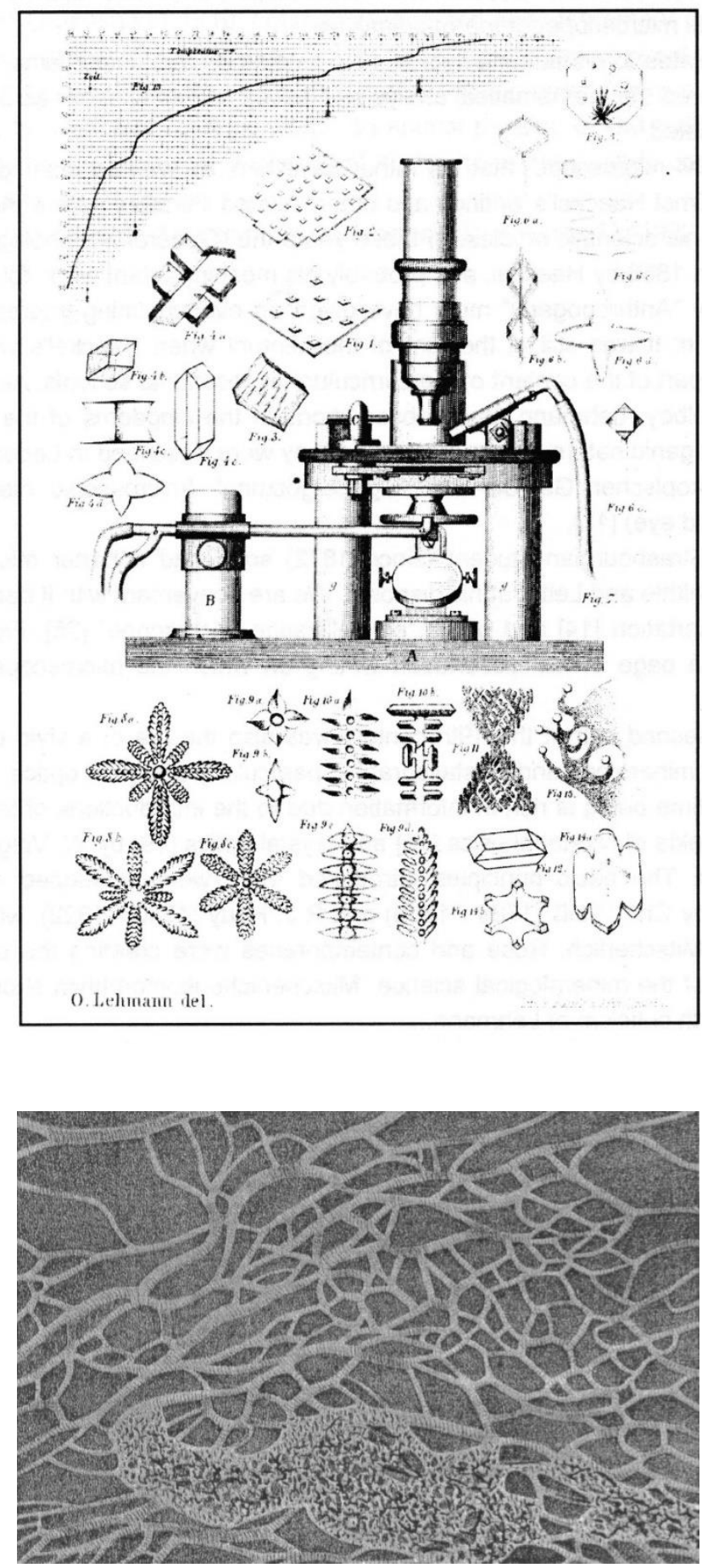

Figure 3. Picture of the "crystallization microscope" of Lehmann accompanied with his own drawings of what he observed, well before he switched to the investigation of liquid crystals. From O. Lehmann, Über Physikalische Isomerie, Inaugural Dissertation, Straßburg (1877).

Figure 4. The first image of a cholesteric liquid crystal texture as published by Lehmann in 1889 [5]. It corresponds to a planar texture with an array of oily streaks. As Lehmann wrote [5]: “.../... [The plastic crystals-so named by Lehmann] therefore appear intensely light blue, or in different circumstances, can generate other different interference colors. Here and there, where the position of the crystals remained unchanged, they appeared bright but run through by bright stripes [the present image]. Because the stripes are in sharp contrast to the light-blue background, they look like bizarre 'oily streaks,' generally pointing along the direction of the prevailing flow." (translation from Ref. [11]). 
he reappeared in the history of LC science some twenty years later, when Lehmann sought to rewrite the genesis of events and claimed priority [9]. Reinitzer defended his pioneering work [10]: "It is indisputably clear that the unambiguous concept of flowing crystals was recognized by Lehmann first of all by studying my derivatives. Furthermore, it is obvious that the perception is due to Lehmann, but I also contributed considerably in this matter.... One should admit that the credit of discovering the phenomenon ought to be attributed to me." (translation from Ref. [11]).

\section{Scientific context}

From 1890 to 1900, Lehmann embarked on an exhaustive program of observations and reproducibility of Reinitzer's experiments with a large number of substances. Lehmann was quickly convinced that the milky liquid had both the characteristics of a crystal and of a liquid and, in 1889, he used the term "crystal that flows." He published numerous papers between 1890 and 1900, and the names followed each other: flowing crystal, viscous liquid crystals, crystalline fluid, and liquid crystals forming drops. Lehmann compiled his scientific literature in a generous treatise published in Leipzig in 1904 and finally entitled "Liquid Crystals" [12]. Lehmann's excessive attachment to the concept of liquid crystals probably contributed to an underestimation of the importance of the discovery and led to errors that required several decades to correct.

We must remember the current vision of matter at the period between the nineteenth and twentieth centuries. Why did the observations and terms used by Lehmann proved to be such a thunderbolt in the scientific community? When Reinitzer discovered liquid crystals, theories on phase transitions and polymorphism were just appearing. Reinitzer and Lehmann had no idea of the molecular composition of cholesterol esters. The very idea of crystalline structure did not exist. The abbot-crystallographer René Just Haüy had introduced the idea of periodic structure for crystals, from which his student Gabriel Delafosse deduced the concept of unit cell in 1840 . This model was 
widely accepted in the late nineteenth century but controversies-such as that between Ernst Mach and Ludwig Boltzmann [13] - about the atomic nature of matter were still active. Major contributions came later from Max von Laue, Nobel Prize in Physics in 1914 "for his discovery of the diffraction of X-rays by crystals," while William Henry Bragg and his son William Lawrence were awarded the Nobel Prize in 1915 "for their services in the analysis of crystal structure by means of X-ray." Therefore, when Lehmann spoke of "liquid crystals," crystallinity and fluidity were considered incompatible, and Lehmann's conclusions about the nature of the strange matter generated much more than skepticism among his colleagues.

\section{The colloidal hypothesis}

Georg Quincke (1834-1924), Gustav Tammann (1861-1938; Figure 5), Georg Wulff (1863-1925), and Walther Nernst (1864-1941) were Lehmann's main opponents from 1890 to 1905.

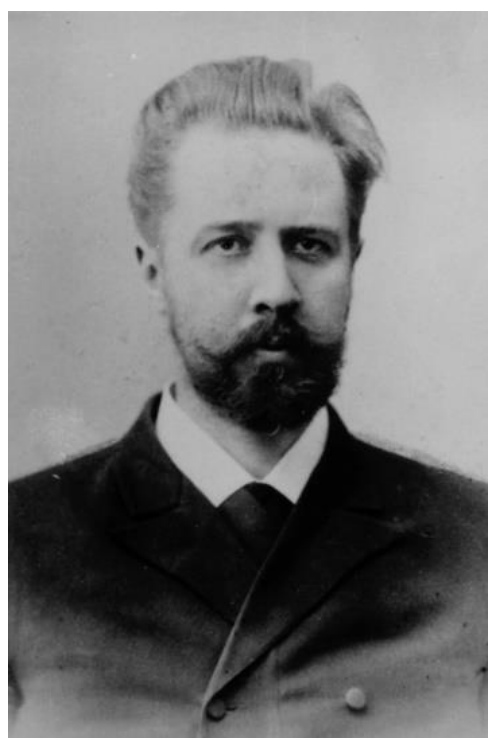

Figure 5. Gustav Tammann was the most vociferous opponent to Lehmann ideas and personality. As late as 1922 he insisted that the so-called liquid crystals were in fact colloidal mixtures.

They clearly challenged the purity of the compounds studied by Lehmann. The turbidity of samples was suspicious. Quincke and Tammann stubbornly claimed that Lehmann's substances were in fact mixtures, and the multiple melting points were simply reflecting the melting points of the different 
ingredients in the mixture. For Quincke and Wulff, these LCs were in fact a colloidal solution, a liquid in which crystalline particles were dispersed, whence the birefringence property of the resulting material. According to them, the milky aspect came from light being scattered by particles in suspension-similar to a milky paint made of pigments suspended in a solvent. The (young) science of colloids had started to boom from the midcentury, and it had become a fashionable research subject. This atmosphere had probably inspired Lehmann's opponents when they searched for explanations. Tammann and Nernst also argued for a colloidal solution, but of a different nature: an emulsion, which is a liquid phase shaped into droplets dispersed in a different liquid-such as milk, which is an emulsion of water and fat. Tammann made an analogy with a water-phenol mixture. Phenol is only partially miscible with water because miscibility depends on the relative concentration and, below a critical temperature, the two liquids phase separate with the consequence that the mixture appears milky. It was essentially the turbid aspect of a "liquid crystal" drop that caused objections and gave rise to the hypotheses of suspension and emulsion. Nevertheless, they did not fit very well with the observations. It would be understood later than the turbidity was due to changes in the average orientation of the molecules from one point to another of the sample, which consisted of many contiguous areas bounded by lines exhibiting optical and structural discontinuity-a polydomain texture, in other (modern) words. Light cannot propagate through the material without being deviated or scattered, which alters the LC transparency.

In 1889, Ludwig Gattermann (1860-1920; Figure 6) and A. Ritschke made the first chemical synthesis of LC molecules: para-azoxyanisole (PAA) and para-azoxyphenetole (PAP). 
Review

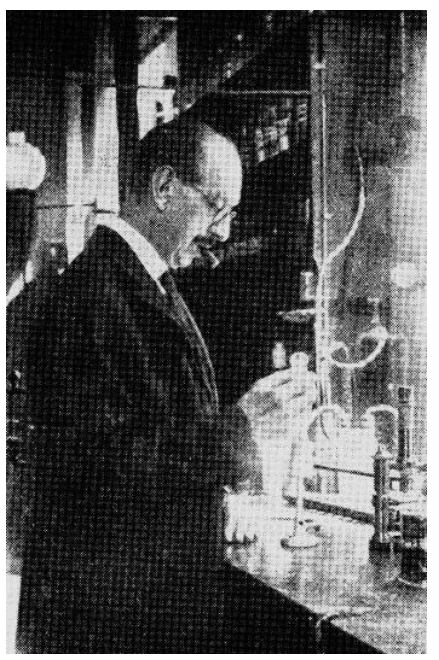

Figure 6. Ludwig Gattermann: his group synthesized the first liquidcrystalline compounds, a result that countered the colloidal hypothesis.

The purity of these compounds was an argument against the hypothesis of poorly controlled mixtures given by Lehmann's opponents. Gattermann and Ritschke published an article in 1890 [14] in which we find for the first time the term "liquid crystal" (Flüssige Kristalle), for which Lehmann would become a passionate promoter. In addition to his use of heterodox terms, Lehmann's links with the ultra-Darwinist Ernst Haeckel (1834-1919) would also detract from his credibility. Haeckel was a zoologist whose view on the theory of evolution was more than controversial. He believed that matter, including inert matter, was endowed with a soul. He spoke literally about "crystal souls" [15]. He was convinced that Lehmann's LCs were the link between the living and the dead; a link he was desperately seeking. After giving a talk at a conference, Lehmann was accosted by a colleague who cruelly questioned him: "What's this about your liquid crystals? Can they now eat?" [11]. Leaving aside the nonscientific claims of Lehmann and Haeckel, we may probably say that they were the first scientists to propound the idea that the LC state is responsible for many of the processes of life [1621]. 


\section{Rising controversy}

The controversy between Lehmman and Tammann, the most virulent of his opponents, continued to rage in the pages of Annalen der Physik between 1900 and 1906. Tammann sarcastically entitled one of his articles "On the so-called liquid crystals" to which Lehmann immediately reacted with an angry article: "Liquid crystals: a refutation of Mr. Tammann's comment."

In 1903, although it did not yet propagate beyond the German community, research on the origin of LC phases was very active. An article on the subject appeared from the group of Daniel Vorländer (1867-1941) in Halle and focused on the classification of compounds based on whether or not they give rise to a LC state [22]. Although Vorländer must have been a coauthor, the article was signed only by his students-Meyer and Dalhem - which in itself is very informative about the climate in the scientific community at the time. Vorländer did not particularly wish to promote the careers of his young collaborators by pushing forward their names. It was rather a precaution, since he was anxious to get away from any eventual new controversy. It is interesting that Vorländer would refer to this paper after 1908 as the paper by "Vorländer, Meyer and Dahlem" [11].

In 1904, electrophoresis experiments excluded the hypothesis of a colloidal fluid [23, 24]: an electric field should separate the particles in suspension in a fluid; however, it had no influence.

In 1905, the knockout blow was delivered to the LC opponents in a conference held in Karlsruhe by the physical chemist Rudolf Schenck (1870-1965; Figure 7), who was very attracted by LC research (fortunately, he did not follow the advice of his mentor Jacob Volhard: "Herr Schenck, leave this stupid stuff" [8]). In his seminar he gave a solid demonstration of a discontinuity in the density and 


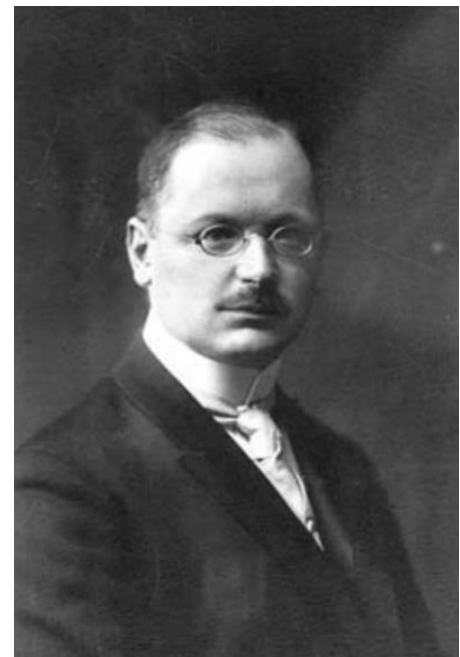

Figure 7. Rudolf Schenck unambiguously demonstrated that liquid crystals were not mixtures, but pure and single compounds.

viscosity at the clearing point, which could not be the behavior of an emulsion. In addition, purification did not change the behavior. "Liquid crystals" did exist. It is said that the moderator of the session, Jacobus Henricus van't Hoff-the first winner of the Nobel Prize in chemistry four years prior, had to deploy treasures of diplomacy to avoid a physical confrontation between Tammann and Schenck. The controversy would gradually die down as from this moment, although an explanation of these famous LCs was still lacking. Van't Hoff proposed to form a committee to discuss the controversy, but the idea came to nothing because Lehmann refused to participate. Lehmann had developed pride and confidence in his own work that led him to take offence when it was challenged [25]. Teamwork with him was impossible [8]. He ruined much of his reputation by an imprudent dogmatism and permanent priggishness [8] - behavior that would not help anyone who seeks to promote revolutionary ideas in science.

In 1907, Vorländer signed-alone this time-an article that would have a long-term influence in the field [26]. It included an essential conclusion: most substances giving rise to LC phases are made with rod-like molecules. The same year, Emil Bose provided the first theory of the LC state, based on the work of Schenck and Vorländer. According to the French mineralogist Frédéric Wallerant, "Lehmann's discovery is definitely one of the most important of the last century. Its consequences are numerous and of the first order. They permit [us] in particular to sharpen our knowledge of crystalline matter." [27]. 
Amazement, doubt, controversy, struggle, and finally acceptance were thus the successive steps of LC research from 1888 to 1907.

\section{Liquid crystals leave Germany}

During the last period of his life (1908-1922), Lehmann worked hard to disseminate the investigations into LCs beyond Germany. In 1909, he was invited to the Sorbonne in Paris to give a long seminar accompanied with experiments [28]. This visit was a great success and gave birth to the French school of LC science, with Charles Mauguin, Georges Friedel, and François Grandjean as pioneers. Until then, French scientists had not succeeded in obtaining a clear representation of Lehmann's descriptions, their efforts being polluted by all sorts of irrelevant considerations. How could one admit that, when sandwiched between two glass plates, a liquid film was able to move on these surfaces while always maintaining at every point, despite the thermal agitation, a constant (optical) axis of symmetry? It seemed simply impossible to them.

In 1922, Friedel published in Annales de Physique a seminal paper of more than two hundred pages [29] that gave the first classification scheme for naming the different phases of LCs: nematic, cholesteric, and smectic. The term cholesteric came from their discovery by Reinitzer in cholesterol esters. A sample of smectic LC (smectos means soap in Greek) behaves like stacked layers that can slide over one another in a manner similar to that of soapy film (which is in fact a LC). Much less known is the true origin of the term "nematic" [30]. One afternoon, when Friedel was relaxing with his daughters, he showed them photographs of LCs taken through a microscope. One daughter, Marie Friedel, who never graduated from high school but maintained her passion for ancient languages to her dying day, shouted with delight upon seeing the abundance of threadlike structures: The Greek word for thread is 'nêmatos'. You should call your liquid crystal 'nematic', Dad! 
Friedel put an end to the confusion by introducing the correct definitions. He vehemently criticized the term "liquid crystal" and advocated for "mesomorphic states," which testified that the phases in question were full states of matter, intermediate (mesos in Greek) between crystalline and liquid phases.

\section{Outlook}

The heroic period of LC science ended in mid-1920s. Paradoxically, LC research started then to decline. LCs were considered by a few decision makers with disdain or irony; a "laboratory curiosity" (strictly speaking) that would never find practical applications. Researchers were encouraged to turn their attention to more fashionable subjects (e.g., quantum mechanics, nuclear physics) if they wished to obtain financial support. Although very valuable research activities into LCs continued, they remained rare and isolated. At this time, LCs were beginning their journey through the desert, which would last until the early 1960s, when people suddenly took out patents for thermography and display applications. "The so strange materials on which Lehmann had the great merit of drawing attention, but he made the mistake to name wrong"-to say it in Friedel's words-started again to focus the attention of the scientific community, but for other reasons now. The great revival occurred in the sixties spurned on by opportunities to use LCs in information-display technology [31, 32]. LCs would revolutionize this domain and give rise to nothing less than the creation of a new industry leading to low-power-consumption flat display screens.

Today it is evident that although LCs are famous for flat screen technology, this sector is only a very narrow niche in comparison with what LCs represent, as a compromise between order and disorder in matter. LCs: give rise to novel molecular designs and structures [33, 34]; raise open questions on the relationship between molecular chirality and structure chirality, or on geometrical frustration in soft condensed matter; play a key role in nondisplay applications $[30,35,36]$ such as 
the formulation of cosmetics (which corresponds to a huge market) and drug-delivery systems (an expanding market), biosensors, microfluidics, smart windows, polarization-independent devices, lenses, stealth technologies, metamaterials, lasing media, adaptive optical interconnects and switches, tunable patch antennas, etc.; are of paramount importance in so many biological processes with a huge number of roles and functions that remain to be discovered. LC science? A tremendous fresh domain of research in matter discovered more than 125 years ago.

[1] F. Reinitzer, Liq. Cryst. 1989, 5, 7-18 (translation from the German of the original paper published in Monatshefte für Chemie 1888, 9, 421-441).

[2] R. Virchow, Virchows Archiv. 1854, 6, 571.

[3] C. Mettenheimer, Corr. blatt d. Vereins gem. Arbeit z. Förd. d. wiss. Heilkunde 1857, 24, 331.

[4] A. Trokhymchuk, Cond. Matt. Phys. 2010, 13, 37002: 1-4.

[5] O. Lehmann, Zeit. für Physikal. Chem. 1889, 4, 462-72.

[6] H. Kelker, Mol. Cryst. Liq. Cryst. 1973, 21, 1-48.

[7] H. Kelker, Mol. Cryst. Liq. Cryst. 1988, 165, 1-43.

[8] P. M. Knoll, H. Kelker, Otto Lehmann-Researcher of the Liquid Crystals, Books on Demand GmbH, Norderstedt, 2010.

[9] O. Lehmann, Annalen der Physik 1908, 25, 852-860.

[10] F. Reinitzer, Annalen der Physik 1908, 27, 213-224.

[11] T. J. Sluckin, D. A. Dunmur, T. J. Sluckin, H. Stegemeyer, Crystals That Flow-Classic Papers from the History of Liquid Crystals, Taylor and Francis, 2004.

[12] O. Lehmann, Flüssige Kristalle sowie Plastizität von Kristallen im allgemeinen, molekulare Umlagerungen und Aggregatzustandsänderungen 1904, Wilhelm Engelmann, Lepizig.

[13] C. Cercignani, Ludwig Boltzmann: The Man Who Trusted Atoms, Oxford University Press, 2006. 
[14] L. Gattermann, A. Ritschke, Ber. Deutsch. Chem. Ges. 1890, 23, 1738-1750.

[15] E. Haeckl, in foreword of Crystal Souls-Studies of Inorganic Life (1917), translated by A. L. Mackay, Forma 1999, 14, 1-240.

[16] J. Needham, Order and Life, Cambridge University Press, 1936.

[17] Y. Bouligand, Liquid Crystalline Order in Biological Materials in Liquid Crystalline Order in Polymers (Ed.: A. Blumstein), Academic Press, New-York, 1978.

[18] A. C. Neville, Biology of Fibrous Composites-Development Beyond the Cell Membrane, Cambridge University Press, 1993.

[19] Structural Biological Materials-Design and Structure-Property Relationship (Ed.: M. Elices) Pergamon, 2000.

[20] Y. Bouligand, Ann. Chim. Sci. Mat. 2004, 29, 83-96.

[21] Y. Bouligand, C. R. Acad. Chimie 2008, 11, 212-220.

[22] F. Meyer, K. Dahlem, Justus Liebigs Ann. Chem. 1903, 326, 331-346.

[23] G. Bredig, N. Schukowsky, Ber. Deutsch. Chem. Ges. 1904, 37, 3419-3425.

[24] G. Coehn, Zeit. für Elecktrochem. 1904, 10, 856-857.

[25] D. Dunmur, T. Sluckin, Soap, Science, \& Flat-Screen TVs-A history of liquid crystals, Oxford University Press, 2011, p. 49.

[26] D. Vorländer, Berichte der Deutschen Chemischen Gesellschaft 1907, 40, 1970-1972.

[27] F. Wallerant, Rivista di Scienza (Bologna) 1907, 1, 221-236.

[28] O. Lehmann, J. de Phys. (Paris) 1909, VIII, 713-735.

[29] G. Friedel, Ann. de Phys. 1922, XVIII, 273-474.

[30] M. Mitov, Sensitive Matter-Foams, Gels, Liquid Crystals and Other Miracles, Harvard University Press, 2012.

[31] J. A. Castellano, Liquid Gold-The Story of Liquid Crystal Displays and the Creation of an Industry, World Scientific, 2005.

[32] T. Geelhaar, K. Griesar, B. Reckmann, Angew. Chem. Int. Ed. 2013, 52, 2-14. 
[33] J. W. Goodby, I. M. Saez,, S. J. Cowling, V. Görtz, M. Draper, A. W. Hall, S. Sia, G. Cosquer, S.E. Lee, E. P. Raynes, Angew. Chem. Int. Ed.2008, 47, 2754-2787.

[34] C. Tschierske, Angew. Chem. Int. Ed. 2013, 52, 8828-8878.

[35] Liquid Crystals -Frontiers in Biomedical Applications (Eds.: S. J. Woltman, G. D. Jay, G. P. Crawford), World Scientific, 2007.

[36] M. Mitov, Adv. Mater. 2012, 24, 6260-6276.

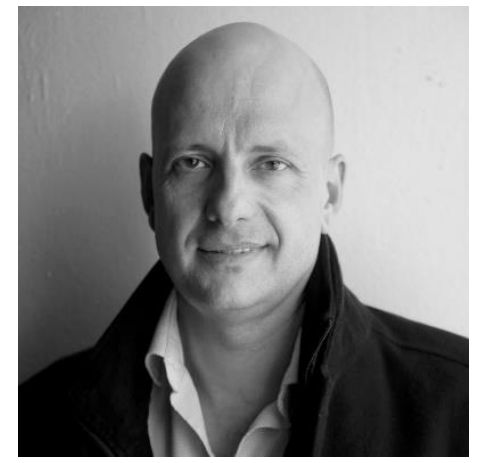

Michel Mitov graduated from the University of Nice-Sophia Antipolis (France), where he received his PhD in condensed matter physics. He is Director of Research at CNRS (National Center for Scientific Research) and leader of the Liquid Crystal Group at Centre d'Elaboration de Matériaux et d'Etudes Structurales in Toulouse. His current interests are the optical and structural properties of cholesteric-liquid-crystalline materials and their use for the self-organization of nanoparticles and biomimetic applications. He is the inventor of patents related to smart reflective windows to control solar light and heat and author of monographs on liquid crystals (Les Cristaux Liquides, Presses Universitaires de France, 2000) and soft matter (Sensitive Matter-Foams, gels, liquid crystals and other miracles, Harvard University Press, USA, 2012). 